Published in final edited form as:

Cardiovasc Intervent Radiol. 2017 May ; 40(5): 761-768. doi:10.1007/s00270-016-1562-4.

\title{
Development of a searchable database of cryoablation simulations for use in treatment planning
}

\author{
F. Edward Boas, MD PhD*, \\ Department of Radiology, Memorial Sloan Kettering Cancer Center, 1275 York Ave., New York, \\ NY 10065 \\ Govindarajan Srimathveeravalli, PhD, \\ Department of Radiology, Memorial Sloan Kettering Cancer Center, 1275 York Ave., New York, \\ NY 10065
}

Jeremy C. Durack, MD,

Department of Radiology, Memorial Sloan Kettering Cancer Center, 1275 York Ave., New York, NY 10065

Elena A. Kaye, PhD,

Department of Medical Physics, Memorial Sloan Kettering Cancer Center, 1275 York Ave., New York, NY 10065

\section{Joseph P. Erinjeri, MD PhD,}

Department of Radiology, Memorial Sloan Kettering Cancer Center, 1275 York Ave., New York, NY 10065

\section{Etay Ziv, MD PhD,}

Department of Radiology, Memorial Sloan Kettering Cancer Center, 1275 York Ave., New York, NY 10065

\section{Majid Maybody, MD,} Department of Radiology, Memorial Sloan Kettering Cancer Center, 1275 York Ave., New York, NY 10065

Hooman Yarmohammadi, MD, and

Department of Radiology, Memorial Sloan Kettering Cancer Center, 1275 York Ave., New York, NY 10065

\section{Stephen B. Solomon, MD}

Department of Radiology, Memorial Sloan Kettering Cancer Center, 1275 York Ave., New York, NY 10065

*corresponding author, boasf@mskcc.org.

srimaths@mskcc.org, durackj@mskcc.org, kayee@mskcc.org, erinjerj@mskcc.org, zive@mskcc.org, maybodym@mskcc.org,

yarmohah@mskcc.org, solomons@mskcc.org

Disclosures:

FEB is a co-founder of Claripacs, LLC, and has received research supplies from Bayer. JCD is on the Scientific Advisory Board and is an investor in Adient Medical. SBS is a PI and HY is a co-PI on a multicenter lung cryoablation trial sponsored by Galil. SBS receives research support from AngioDynamics and GE Healthcare. 


\section{Abstract}

Purpose-To create and validate a planning tool for multiple-probe cryoablation, using simulations of ice ball size and shape for various ablation probe configurations, ablation times, and types of tissue ablated.

Materials and methods-Ice ball size and shape was simulated using the Pennes bioheat equation. 5670 different cryoablation procedures were simulated, using 1-6 cryoablation probes and 1-2 $\mathrm{cm}$ spacing between probes. The resulting ice ball was measured along three perpendicular axes and recorded in a database. Simulated ice ball sizes were compared to gel experiments (26 measurements) and clinical cryoablation cases (42 measurements). The clinical cryoablation measurements were obtained from a HIPAA-compliant retrospective review of kidney and liver cryoablation procedures between January 2015 and February 2016. Finally, we created a web-based cryoablation planning tool, which uses the cryoablation simulation database to look up the probe spacing and ablation time that produces the desired ice ball shape and dimensions.

Results-Average absolute error between the simulated and experimentally measured ice balls was $1 \mathrm{~mm}$ in gel experiments, and $4 \mathrm{~mm}$ in clinical cryoablation cases. The simulations accurately predicted the degree of synergy in multiple-probe ablations. The cryoablation simulation database covers a wide range of ice ball sizes and shapes up to $9.8 \mathrm{~cm}$.

Conclusion-Cryoablation simulations accurately predict the ice ball size in multiple-probe ablations. The cryoablation database can be used to plan ablation procedures: given the desired ice ball size and shape, it will find the number and type of probes, probe configuration and spacing, and ablation time required.

\section{Introduction}

Cryoablation is used to treat tumors in the kidney [1], prostate [2], liver [3], lung [4], breast [5], soft tissue [6], and bone [7]. Compared to heat-based ablation (microwave and radiofrequency), cryoablation can result in less pain, less damage to adjacent critical structures such as the renal collecting system, and better intra-procedural monitoring via visualization of the ice ball on CT, ultrasound, or MRI [8]. The mechanism of cell death is a combination of osmotic dehydration from extracellular ice formation, cell rupture from intracellular ice formation, and ischemia from vascular injury $[9 ; 10]$.

Typically, the instructions for use for cryoablation probes [11] only provide the size of the ice ball for a single probe at a single ablation time point. For a smaller tumor, a shorter ablation time with a single probe may be required to avoid damage to surrounding structures. For a larger tumor, multiple probes may be required to completely ablate the tumor. Unfortunately, limited information is available on the expected ice ball size for multiple probes, and for nonstandard ablation times. In multiple-probe ablation, there is a variable amount of synergy between the probes, which can result in a larger ablation zone than expected $[12 ; 13]$.

Cryoablation simulations using the Pennes bioheat equation, which models heat diffusion and tissue perfusion on a 3D grid, can accurately predict the ice ball size in ex vivo and in 
vivo liver cryoablation [14]. However, accurate simulations are too slow for routine clinical use, and simple ice ball models are inaccurate due to synergy between probes [12].

Here we create a planning tool for multiple-probe cryoablation that overcomes the limitations of prior approaches by pre-computing the ice ball size for thousands of potential probe configurations and ablation times, using the Pennes bioheat equation. We evaluate whether this approach allows for both rapid and accurate estimation of the ice ball size.

The interventional radiologist tells the planning tool the desired ice ball size (in three dimensions) and the type of tissue being ablated. The planning tool then searches for the closest match in a database of thousands of simulated cryoablation procedures, and tells the interventional radiologist the number of probes to use, type of probe, probe spacing, probe configuration, and ablation time. We use several metrics to evaluate this planning tool: speed of generating a treatment plan (seconds), accuracy of ice ball sizes in the database ( $\mathrm{mm}$ ), and database coverage (percentage of tridimensional ice ball sizes with a close match in the database).

\section{Materials and methods Cryoablation simulations}

Ice ball size and shape was simulated using the Pennes bioheat equation [14], which includes heat diffusion and tissue perfusion:

$$
c \frac{\partial T}{\partial t}=\frac{k}{\rho} \nabla^{2} T+\frac{\omega c_{b} \rho_{b}}{\rho}\left(T_{a}-T\right)
$$

$T=$ temperature $\left({ }^{\circ} \mathrm{C}\right)$

$t=$ time $(\mathrm{s})$

$k=$ thermal conductivity $\left(\mathrm{W} / \mathrm{cm} /{ }^{\circ} \mathrm{C}\right)$

$\rho=$ mass density (tissue, $\mathrm{g} / \mathrm{ml}$ )

$\rho_{b}=$ mass density (blood, $\left.\mathrm{g} / \mathrm{ml}\right)$

$c=$ specific heat capacity (tissue, $\mathrm{J} / \mathrm{g} /{ }^{\circ} \mathrm{C}$ ), including the specific heat of fusion of water at $0^{\circ} \mathrm{C}$

$c_{b}=$ specific heat capacity $\left(\right.$ blood, $\mathrm{J} / \mathrm{g} /{ }^{\circ} \mathrm{C}$ )

$\omega=$ volumetric blood flow per volume of tissue $\left(\mathrm{s}^{-1}\right)$

$T_{a}=$ arterial blood temperature $=37^{\circ} \mathrm{C}$

Simulations were performed on a $10 \times 10 \times 10 \mathrm{~cm}$ isotropic 3D grid with $1 \mathrm{~mm}$ voxel size, using a standard finite difference method, and published values for tissue-specific thermal conductivity, heat capacity, water content, and perfusion (Table 1). Each voxel is assigned a 
tissue type and temperature, and voxels at $0^{\circ} \mathrm{C}$ may be partially frozen. The initial and boundary temperatures were set to $37^{\circ} \mathrm{C}$. We developed custom multi-threaded software written in $\mathrm{C}++$ to perform the simulations.

\section{Cryoablation configurations}

5670 different simulations were performed of all possible combinations of: 5 tissue types (kidney, liver, muscle, fat, and water), 2 ablation probe types (Galil IceRod Plus 1.5 or IceSphere), 21 probe configurations with up to 6 probes and $1-2 \mathrm{~cm}$ probe spacing (Figure 1 and Figure 2), and 27 ablation schedules (Table 2). Freezing was performed at 100\% power. All probes were placed in an axial plane, because this is the easiest plane for placing probes under CT guidance.

For each simulation, axial and coronal images of the ice ball were generated. The ice ball was measured along three perpendicular axes $\left(0^{\circ} \mathrm{C}\right.$ and $-20^{\circ} \mathrm{C}$ isotherms). The distance that the ice ball extended beyond the tip of the probe was also measured.

\section{Comparison to in vitro data (cryoablation in gel)}

Simulated ice ball sizes were compared to experimental ice ball sizes, using experimental data supplied by the manufacturer on 1-4 probe ablations (IceRod Plus and IceSphere) in gel, with 1-2 cm spacing between probes, with a 10 minute freeze, followed by a 5 minute passive thaw, followed by a 10 minute freeze [15].

We also evaluated the amount of synergy in multiple-probe ablations, and compared the amount of synergy in the experimental data to the simulations. Synergy is defined as the ice ball size in a multiple-probe ablation, minus the expected size based on the union of singleprobe ice balls. For example, if a single cryoablation probe produces a $3 \mathrm{~cm}$ spherical ice ball, then in the absence of synergy, two parallel cryoablation probes placed $1 \mathrm{~cm}$ apart in the axial plane would be expected to produce a $4 \mathrm{~cm}$ (axial, perpendicular to the probes) $\times 3$ $\mathrm{cm}$ (axial, parallel to the probes) $\times 3 \mathrm{~cm}$ (superior to inferior) ice ball. If the actual ice ball measures $4.2 \times 3.5 \times 4.1 \mathrm{~cm}$, then there is $0.2 \mathrm{~cm}$ synergy in the axial plane (perpendicular to the probes), $0.5 \mathrm{~cm}$ synergy in the axial plane (parallel to the probes), and $1.1 \mathrm{~cm}$ synergy in the superior-to-inferior direction.

\section{Comparison to clinical data (cryoablation in kidney and liver)}

Retrospective evaluation of clinical cryoablation cases was approved by the Institutional Review Board. The probe configuration and ice ball size was examined for all clinical kidney and liver cryoablation procedures performed using Galil IceRod Plus or IceSphere or Endocare PCS-24 probes between January 2015 and February 2016. The probe coordinates and ice ball size (in the $x, y$, and $z$ directions) were measured on the CT or MRI images obtained during the cryoablation procedure. Cryoablation simulations were performed using the cryoablation probe configuration, the thermal properties of the target organ (kidney or liver), and the ablation time specified in the procedure report. 


\section{Statistical analysis}

Average absolute error and the coefficient of determination $\left(r^{2}\right)$ between experimental and simulated ice ball sizes (in the $x, y$, and $z$ directions) was calculated for both in vitro (gel) and in vivo (clinical) experimental data. The standard error of the average error measurement was also calculated.

\section{Planning tool}

We created a cryoablation planning tool, which searches through the 5670 cryoablation simulations to find the probe spacing and ablation time that produces the desired ice ball shape and dimensions. Simulations with gaps in the ice ball between probes are excluded from the search results. The planning tool was evaluated for speed and coverage. To determine coverage, the average and maximum error between the desired ice ball size, and the closest match produced by the planning tool was calculated, for any desired ice ball size $a \times b \times c \mathrm{~cm}$ (where each dimension is between 3 and $6 \mathrm{~cm}$ ). The cryoablation planning tool was written in Javascript, and is available for free on the web.

\section{Results}

\section{Comparison to in vitro data (cryoablation in gel)}

The cryoablation simulations accurately predicted the size of the ice ball in gel experiments, with $r^{2}=0.98$ (Figure 3). Average error between the simulated and experimentally measured ice balls was $1.1 \mathrm{~mm}$ ( 26 measurements). The range of errors was $0-2.9 \mathrm{~mm}$, median error was $1.0 \mathrm{~mm}$, and the standard error of the average error measurement was $0.2 \mathrm{~mm}$.

We also tested whether the simulations could predict the amount of synergy in a multipleprobe ablation. Experimentally, the ice ball in a multiple-probe ablation was up to $1.2 \mathrm{~cm}$ bigger than expected (based on the single-probe ice ball size), due to synergy between the probes. The amount of synergy depends on the number of probes, spacing between probes, and the type of cryoablation probe. The cryoablation simulations accurately predicted the degree of synergy between probes (Figure 4).

\section{Comparison to clinical data (cryoablation in kidney and liver)}

15 cryoablation procedures met the inclusion criteria. 1 MRI-guided liver cryoablation procedure was excluded due to inability to distinguish the positons of adjacent probes. The remaining 14 procedures consisted of 3 MRI-guided liver cryoablation procedures and 11 CT-guided renal cryoablation procedures, using 1-6 probes per procedure.

The cryoablation simulations accurately predicted the size of the ice ball in clinical cases, with $r^{2}=0.87$ (Figure 5 and Figure 6). Average error between the simulated and measured ice balls was $3.5 \mathrm{~mm}$ ( 42 measurements). The range of errors was $0-10 \mathrm{~mm}$, median error was $3.5 \mathrm{~mm}$, and standard error of the average error measurement was $0.4 \mathrm{~mm}$.

\section{Planning tool}

The cryoablation simulation database covers a wide range of ice ball sizes and shapes up to $9.8 \mathrm{~cm}$, with aspect ratios (long axis length / short axis length) ranging from 1 to 3.7. For 
any desired ice ball size $a \times b \times c \mathrm{~cm}$, where each dimension is between 3 and $6 \mathrm{~cm}$, there is always a match in the database within $0.9 \mathrm{~cm}$, and the average match is within $0.2 \mathrm{~cm}$. In other words, the database has $100 \%$ coverage of all tridimensional ice ball sizes between 3 and $6 \mathrm{~cm}$, to within $0.9 \mathrm{~cm}$. Thus, the database includes a wide range of spherical, prolate spheroid (cigar-shaped), and oblate spheroid (pancake-shaped) ice balls. Smaller subsets of the full database resulted in less coverage (Figure 7).

The planning tool is available for free on the web (Figure 8). Average search time is 0.34 seconds (including retrieving axial and coronal images of the simulated ice ball), when accessed from a computer 2500 miles away from the web server. For comparison, a single 25 min cryoablation procedure takes 35 minutes to simulate on a modern 4-core CPU.

\section{Discussion}

We show that cryoablation simulations can accurately predict the ice ball size in multipleprobe ablations. In particular, there is a variable amount of synergy between probes, which is accurately predicted by the simulations. Ice ball size in gel was predicted with an average error of $1 \mathrm{~mm}$, and ice ball size in clinical kidney and liver cryoablation procedures was predicted with an average error of $4 \mathrm{~mm}$. The higher error in clinical procedures could be due to several factors, including inaccurate perfusion estimates in kidney and liver, local variations in perfusion due to large vessels [16] or surrounding fat, patient motion, and measurement error in the $z$-direction due to the CT or MRI slice thickness $(5 \mathrm{~mm}$ in all cases).

We also present a new strategy for planning cryoablation procedures. Our strategy combines the accuracy of cryoablation simulations using the Pennes bioheat equation [14], with the speed of using a large pre-computed database of simulated cryoablation procedures. Given the desired ice ball size and shape and the organ to be ablated, the planning tool will search the database for the number and type of probes, probe configuration and spacing, and ablation time required. The database has good coverage over a wide range of desired ice ball sizes.

Experienced users may already have an intuitive feel for how certain cryoablation probes will behave, and might have less use for this planning tool. However, less experienced users, or experienced users using an unfamiliar type of ablation probe, should find utility in this database, which shows how different cryoablation probes perform under a wide variety of conditions. Less experienced users of radiofrequency ablation have a higher complication rate, and a lower complete ablation rate $[17 ; 18]$, and experience might also affect outcomes after cryoablation [19]. Future studies should examine whether planning tools help reduce complications and local recurrences, especially for less experienced users.

There are several limitations of the current study. The cryoablation simulations take into account the thermal properties of different types of tissue, the temperature dependence of thermal properties, and cold sink effects due to small vessel perfusion [20]. However, they currently do not model cold sink due to large vessels, which can result in incomplete ablation around the large vessel [16]. We assume that thermal conductivity and specific heat 
capacity have a linear temperature dependence, which might not be accurate for extremely cold temperatures, and in some cases, we did not have any data on the temperature dependence. The simulations assume uniform tissue properties in the ablation zone. In reality, the surrounding fat, muscle, or hydrodissection fluid has different thermal and perfusion properties compared to the ablated organ, and the tumor being ablated might also have different properties compared to normal tissue. Finally, even though the database contains thousands of different probe configurations and ablation times, it is still not comprehensive.

Future work should evaluate the utility of this planning tool in a clinical setting. In particular, the impact of this tool on procedure time, ablation margins, complications, and number of probes used should be examined. Future versions of the tool could overlay the planned probe positions onto the pre-ablation CT or MRI images, include more probe types, model large vessel cold sinks, and allow for interpolation between different probe positions or ablation times.

\section{Acknowledgements}

We thank Vineel Vallapureddy, Sonja Foss, Luan Chan, Satish Ramadhyani, and Uri Arbel at Galil for providing the experimental data on ice ball sizes. This research was funded in part through an NIH/NCI Cancer Center Support Grant (P30 CA008748).

\section{References}

1. Zargar H, Atwell TD, Cadeddu JA, et al. Cryoablation for Small Renal Masses: Selection Criteria, Complications, and Functional and Oncologic Results. Eur Urol. 2016; 69(1):116-128. [PubMed: 25819723]

2. Valerio M, Ahmed HU, Emberton M, et al. The role of focal therapy in the management of localised prostate cancer: a systematic review. Eur Urol. 2014; 66(4):732-751. [PubMed: 23769825]

3. Littrup PJ, Aoun HD, Adam B, Krycia M, Prus M, Shields A. Percutaneous cryoablation of hepatic tumors: long-term experience of a large U.S. series. Abdom Radiol (NY). 2016; 41(4):767-780. [PubMed: 26960728]

4. de Baere T, Tselikas L, Woodrum D, et al. Evaluating Cryoablation of Metastatic Lung Tumors in Patients--Safety and Efficacy: The ECLIPSE Trial--Interim Analysis at 1 Year. J Thorac Oncol. 2015; 10(10):1468-1474. [PubMed: 26230972]

5. Simmons RM, Ballman KV, Cox C, et al. A Phase II Trial Exploring the Success of Cryoablation Therapy in the Treatment of Invasive Breast Carcinoma: Results from ACOSOG (Alliance) Z1072. Ann Surg Oncol. 2016; 23(8):2438-2445. [PubMed: 27221361]

6. Maybody M, Tang PQ, Moskowitz CS, Hsu M, Yarmohammadi H, Boas FE. Pneumodissection for skin protection in image-guided cryoablation of superficial musculoskeletal tumours. Eur Radiol. 2016

7. Callstrom MR, Dupuy DE, Solomon SB, et al. Percutaneous image-guided cryoablation of painful metastases involving bone: multicenter trial. Cancer. 2013; 119(5):1033-1041. [PubMed: 23065947]

8. Hinshaw JL, Lubner MG, Ziemlewicz TJ, Lee FT Jr. Brace CL. Percutaneous tumor ablation tools: microwave, radiofrequency, or cryoablation--what should you use and why? Radiographics. 2014; 34(5):1344-1362. [PubMed: 25208284]

9. Erinjeri JP, Clark TW. Cryoablation: mechanism of action and devices. J Vasc Interv Radiol. 2010; 21(8 Suppl):S187-191. [PubMed: 20656228]

10. Chu KF, Dupuy DE. Thermal ablation of tumours: biological mechanisms and advances in therapy. Nat Rev Cancer. 2014; 14(3):199-208. [PubMed: 24561446] 
11. [Accessed 2015-10-02] Available at http://www.galilmedical.com/cryoablation-products/ifus/

12. Young JL, McCormick DW, Kolla SB, et al. Are multiple cryoprobes additive or synergistic in renal cryotherapy? Urology. 2012; 79(2):484, e481-486.

13. Littrup PJ, Jallad B, Vorugu V, et al. Lethal isotherms of cryoablation in a phantom study: effects of heat load, probe size, and number. J Vasc Interv Radiol. 2009; 20(10):1343-1351. [PubMed: 19695903]

14. Kim C, O'Rourke AP, Mahvi DM, Webster JG. Finite-element analysis of ex vivo and in vivo hepatic cryoablation. Ieee T Bio-Med Eng. 2007; 54(7):1177-1185.

15. Shah TT, Arbel U, Foss S, et al. Modeling Cryotherapy Ice-Ball Dimensions and Isotherms in a Novel Gel Based Model to Determine Optimal Cryo-Needle Configurations and Settings for Potential Use in Clinical Practice. Urology. 2016 In press.

16. Shyn PB, Mauri G, Alencar RO, et al. Percutaneous imaging-guided cryoablation of liver tumors: predicting local progression on 24-hour MRI. AJR Am J Roentgenol. 2014; 203(2):W181-191. [PubMed: 24555531]

17. Poon RT, Ng KK, Lam CM, et al. Learning curve for radiofrequency ablation of liver tumors: prospective analysis of initial 100 patients in a tertiary institution. Ann Surg. 2004; 239(4):441449. [PubMed: 15024304]

18. Lee TY, Lin JT, Ho HJ, Wu MS, Wu CY. Evaluation of the Effect of Cumulative Operator Experience on Hepatocellular Carcinoma Recurrence after Primary Treatment with Radiofrequency Ablation. Radiology. 2015; 276(1):294-301. [PubMed: 25763830]

19. Schmit GD, Atwell TD, Callstrom MR, et al. Percutaneous cryoablation of renal masses $\geq 3 \mathrm{~cm}$ : efficacy and safety in treatment of 108 patients. J Endourol. 2010; 24(8):1255-1262. [PubMed: 20380510]

20. Chen MM, Holmes KR. Microvascular contributions in tissue heat transfer. Ann N Y Acad Sci. 1980; 335:137-150. [PubMed: 6931512]

21. Hasgall, PA., Di Gennaro, F., Baumgartner, C., et al. [Accessed 2015] IT'IS database for thermal and electromagnetic parameters of biological tissues. Available at http://www.itis.ethz.ch/itis-forhealth/tissue-properties/downloads/

22. Kreith, F., Goswami, DY. The CRC handbook of mechanical engineering. CRC Press; Boca Raton Fla.: 2005.

23. Lide, DR. CRC Handbook of Chemistry and Physics. CRC Press; 2000.

24. WolframAlpha. [Accessed 2015] Available at http://www.wolframalpha.com

25. Snyder WS, Cook MJ, Nasset ES, Karhausen LR, Howells GP, Tipton IH. Report of the task group on reference man. Annals of the ICRP/ICRP Publication. 1975; 23:1-480. 


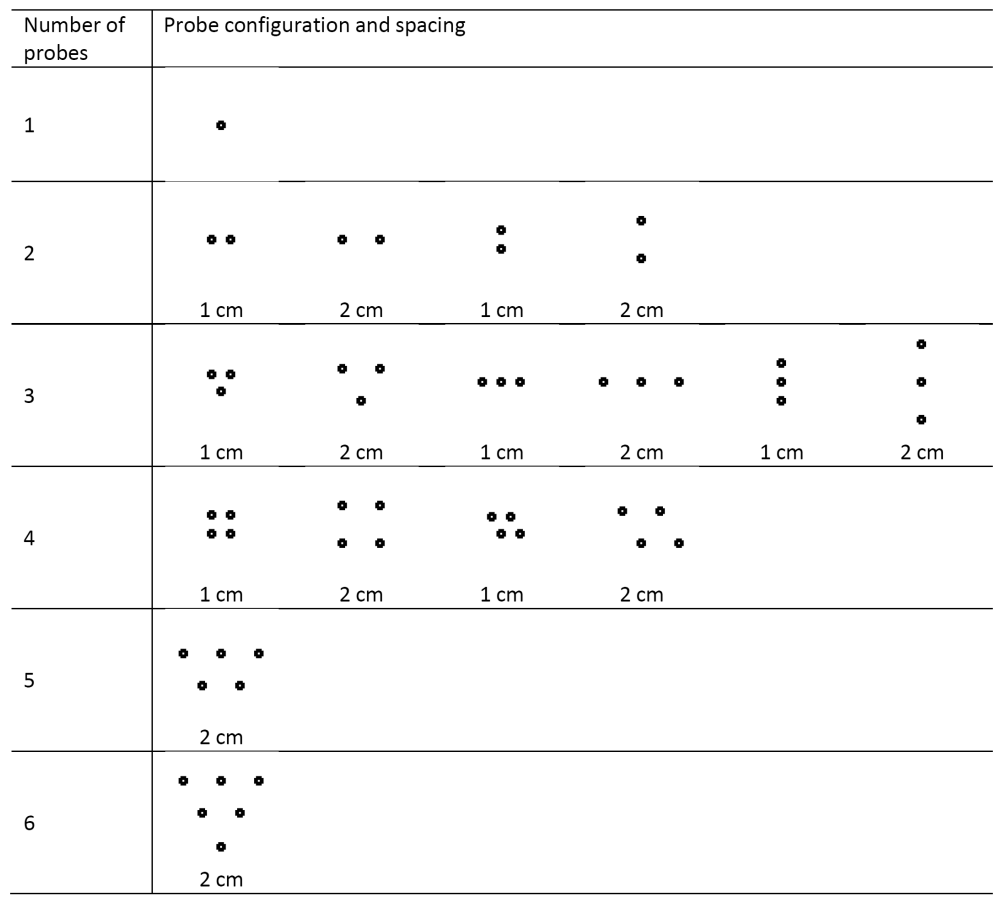

Figure 1.

Parallel probe configurations in the cryoablation simulation database (coronal images). 1-6 probes are placed with 1-2 $\mathrm{cm}$ spacing between adjacent probes. 

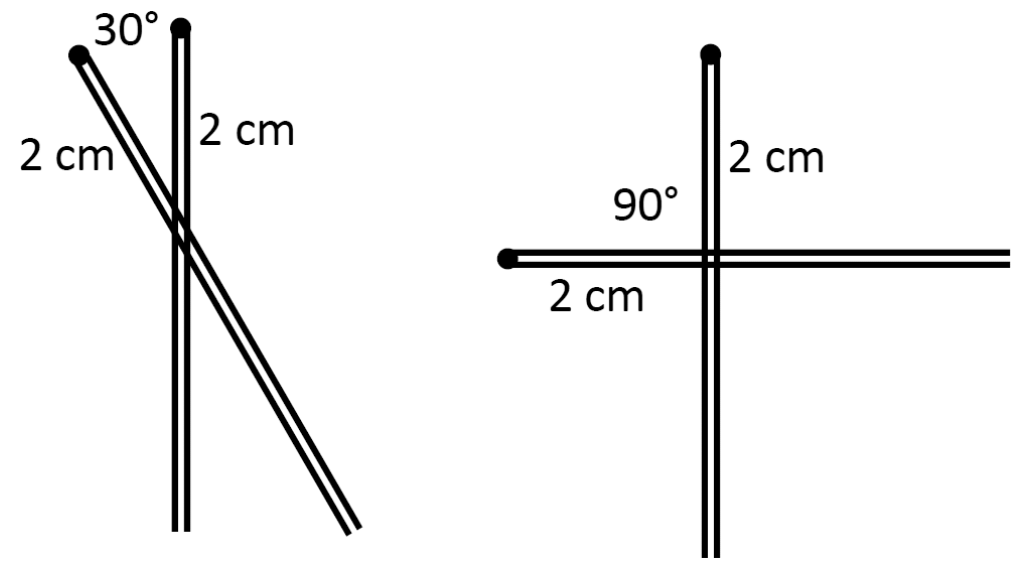

Figure 2.

Non-parallel probe configurations in the cryoablation simulation database. 2-3 probes are placed in different axial planes spaced $2 \mathrm{~cm}$ apart, with alternating angles of approach separated by $30^{\circ}$ or $90^{\circ}$. Schematic diagram shows the view from the top. 


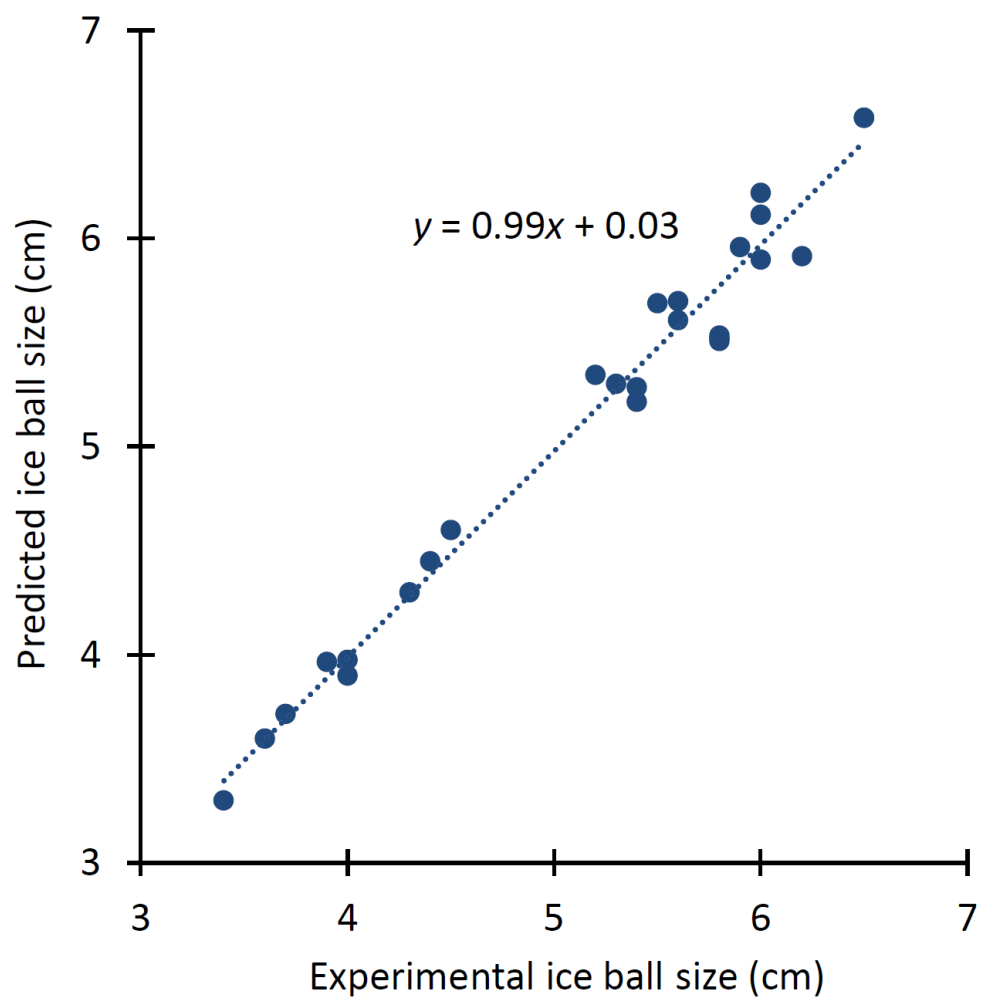

Figure 3.

Experimental versus predicted ice ball measurements for 1-4 probe ablations (IceRod Plus and IceSphere) in gel, with 1-2 cm spacing between probes. $r^{2}=0.98, p=4.8 \times 10^{-21}$. 


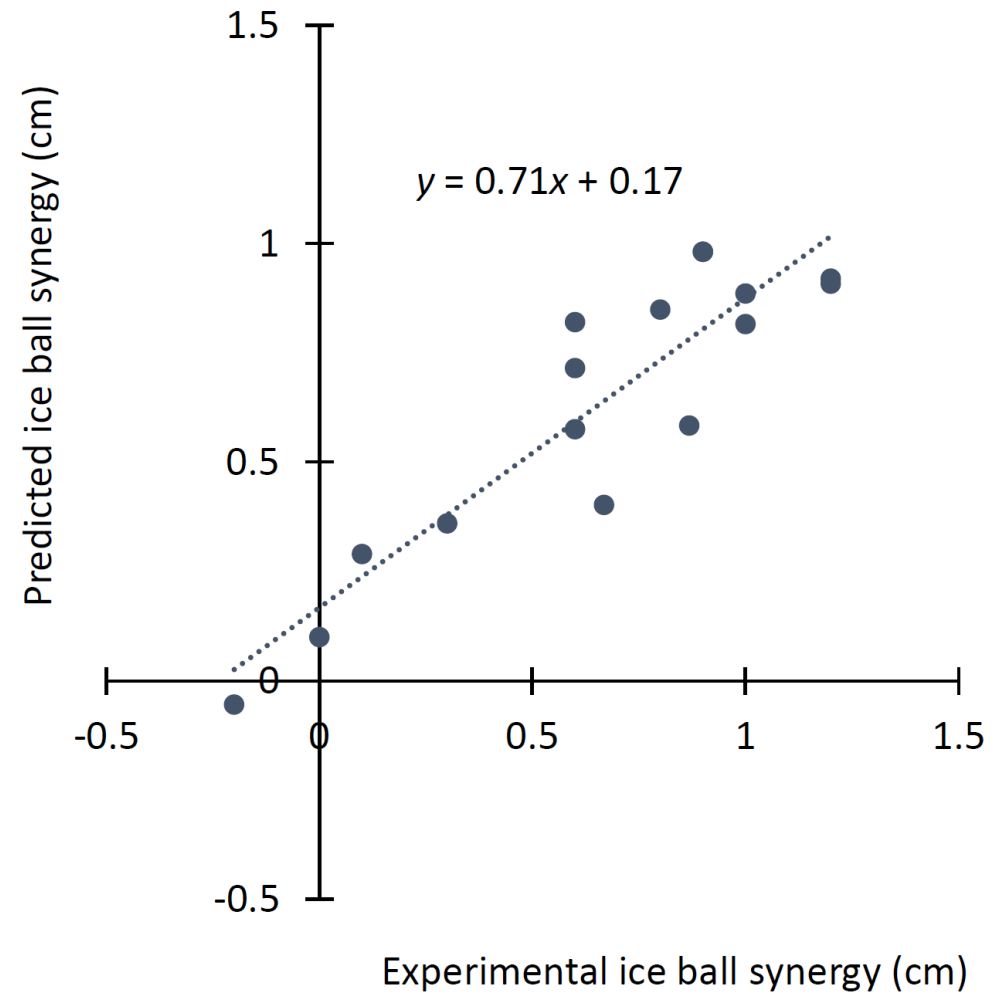

Figure 4.

Experimental versus predicted amount of synergy in multiple-probe ablations in gel. Synergy is defined as the ice ball size in a multiple-probe ablation, minus the expected size based on the union of single-probe ice balls. $r^{2}=0.83, p=1.1 \times 10^{-6}$. 


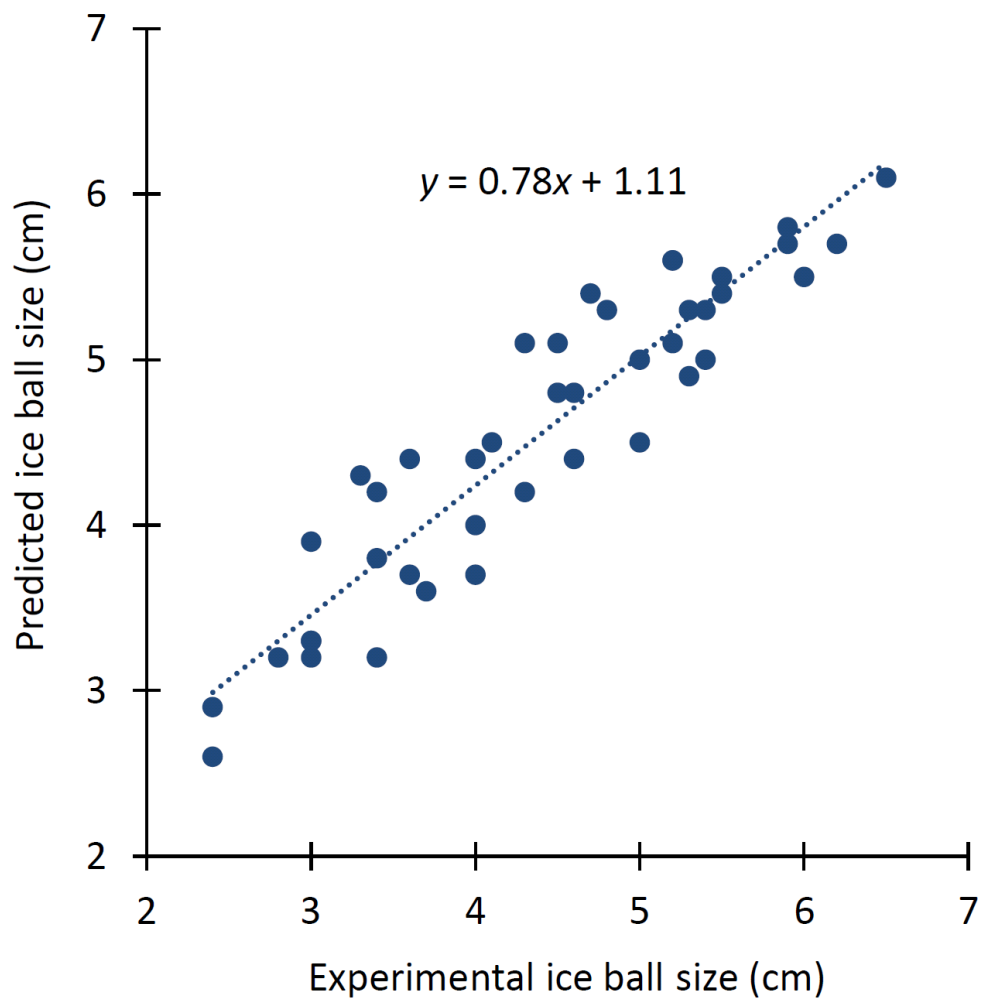

Figure 5.

Experimental versus predicted ice ball measurements for 1-6 probe clinical cryoablation procedures in kidney and liver. $r^{2}=0.87, p=5.5 \times 10^{-19}$. 

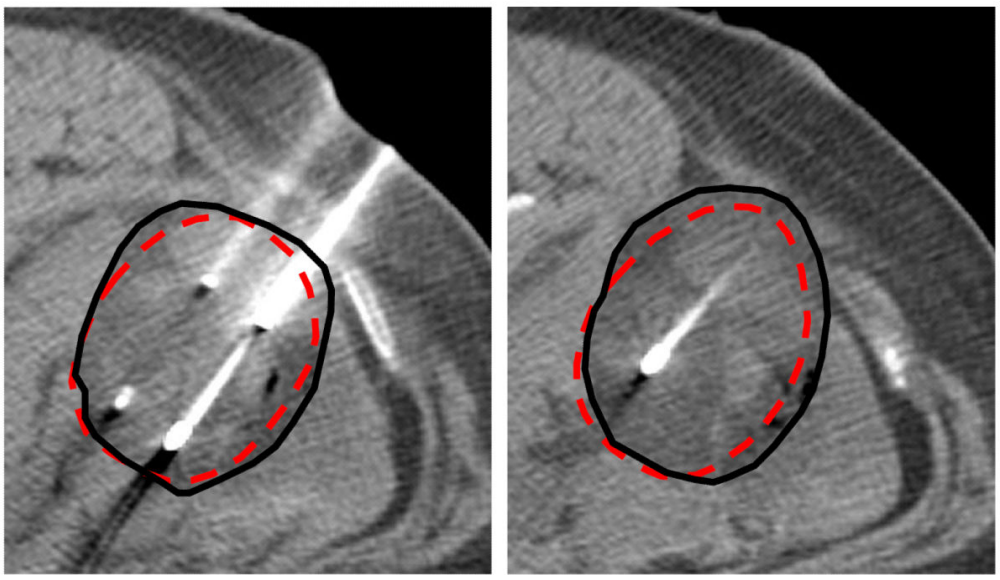

Figure 6.

Actual (solid black line) and predicted (dashed red line) ice balls in a 3-probe renal cryoablation procedure. The correlation between actual and predicted ice ball sizes is shown in Figure 5. 


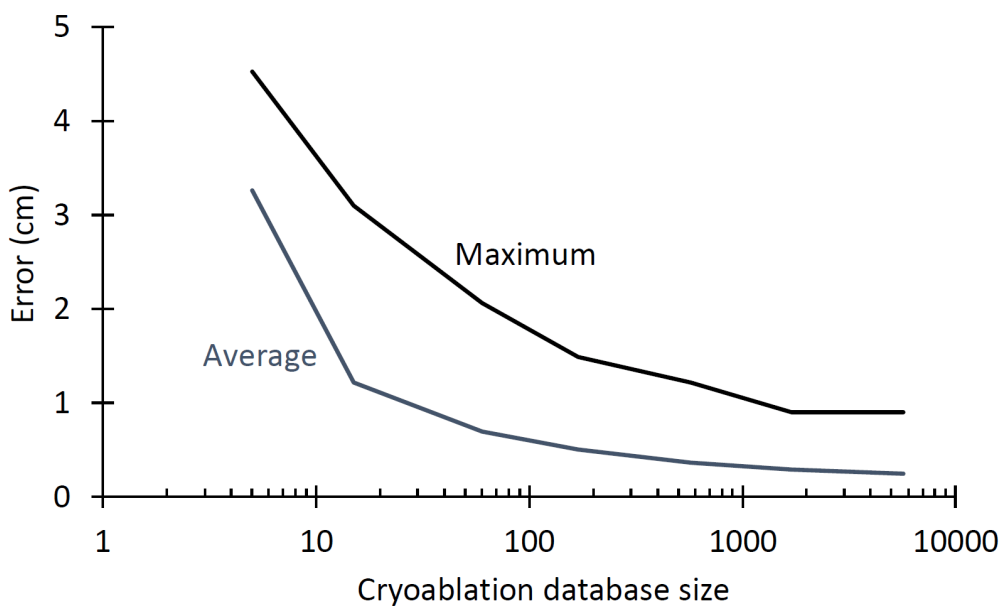

Figure 7.

Database coverage versus database size. For all 3-6 cm ice balls (measured along 3 dimensions), the average and maximum difference between the desired ice ball size and the closest match in the database are shown, as a function of the number of simulations in the cryoablation database. 


\begin{tabular}{|c|c|c|}
\hline \multicolumn{3}{|l|}{ Tissue type: Liver } \\
\hline axial & axial & superior-inferior \\
\hline Desired ice ball size: 7.5 & $\mathrm{x} 6$ & $x 6$ \\
\hline
\end{tabular}

\section{Search}

Closest match:

Size of ice ball $\left(0^{\circ} \mathrm{C}\right): 7.3 \times 6.2 \times 5.7 \mathrm{~cm}$, extending $1.5 \mathrm{~cm}$ beyond the tip of the probe. Size of ice ball $\left(-20^{\circ} \mathrm{C}\right): 6.9 \times 5.7 \times 5.3 \mathrm{~cm}$.

Probe: IceRod Plus 1.5

Probe configuration: 5 probes, $2 \mathrm{~cm} \mathrm{~W}$

Ablation time: Freeze for 10 minutes, passive thaw for 5 minutes, freeze for 15 minutes.

Axials:

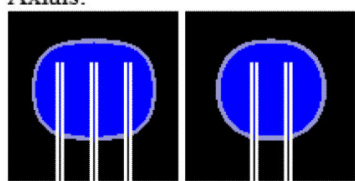

Coronal:

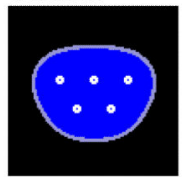

Figure 8.

Web-based cryoablation planning tool, available at [redacted for anonymous peer review].

The user fills in the information above the "Search" button, and the planning tool generates the treatment plan shown below the "Search" button. The $0^{\circ} \mathrm{C}$ ice ball is shown in light blue, and the $-20^{\circ} \mathrm{C}$ ice ball is shown in blue. Currently supported tissue types are: muscle, liver, kidney, fat, cortical bone, water, air, and steel (in the cryoablation probe). 


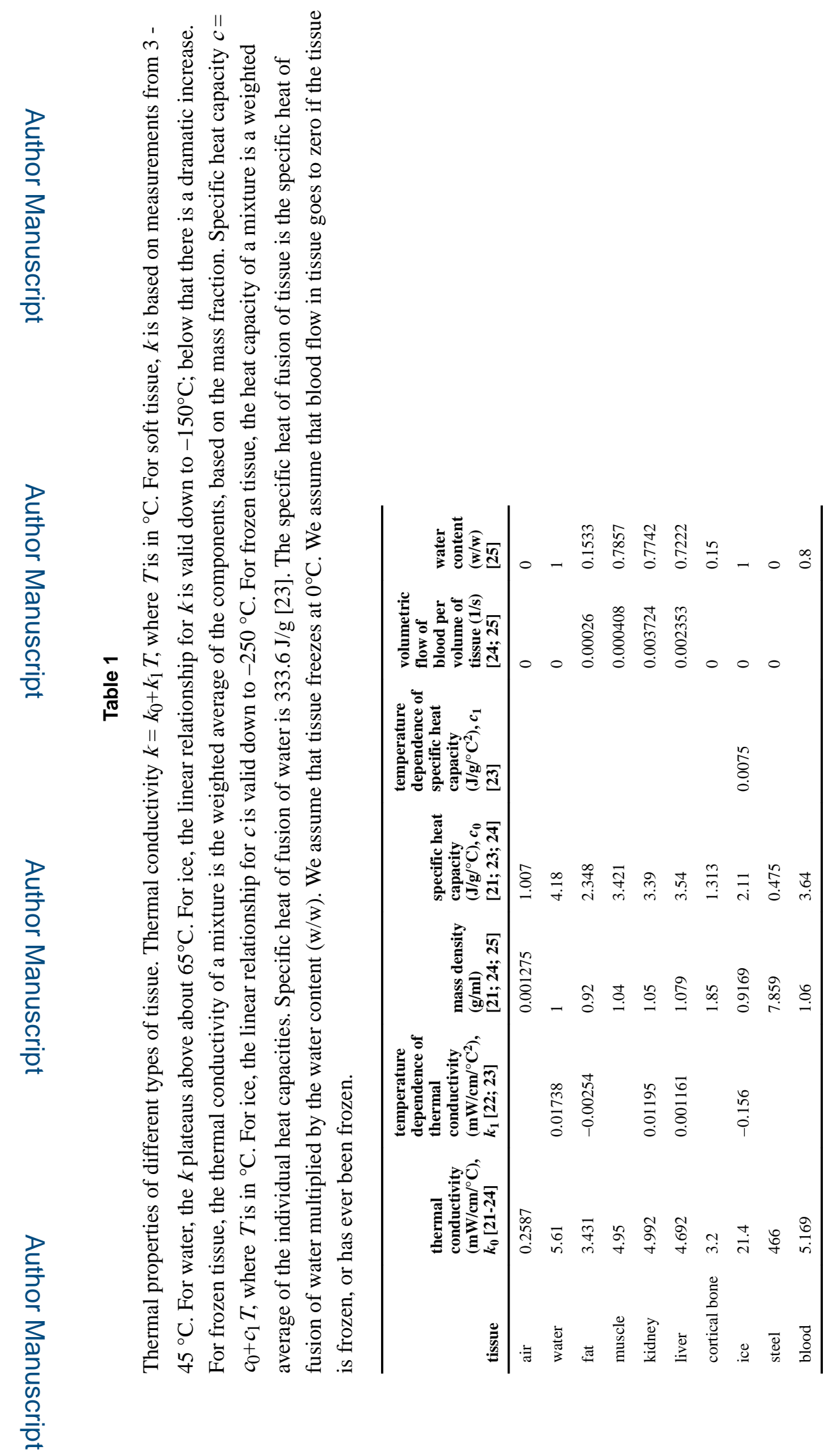

Cardiovasc Intervent Radiol. Author manuscript; available in PMC 2018 May 01. 


\section{Table 2}

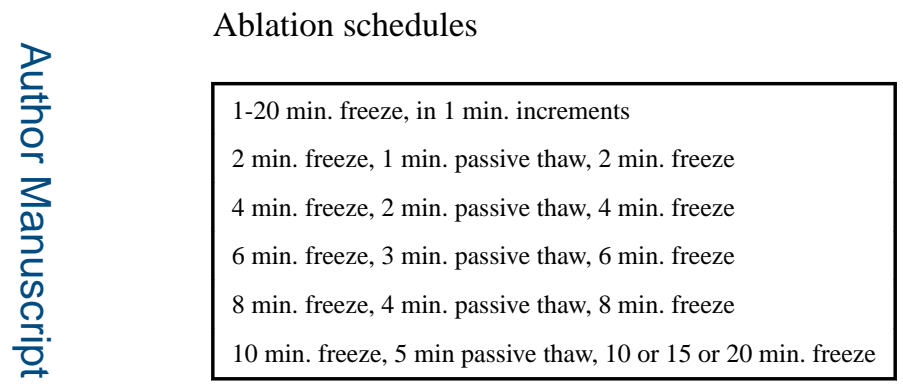

